\title{
Akut Aort Diseksiyonu Tanısı ile Cerrahi Tedavisi Yapılan Hastalara Ait Erken ve Orta Dönem Sonuçları
}

\author{
The Early and Mid-Term Results of Surgical Treatment in Patients Diagnosed \\ with Acute Aortic Dissection
}

\author{
Cengiz OVALI' ${ }^{1}$, M. Behçet SEVIN ${ }^{1}$ \\ ${ }^{1}$ Eskişehir Osmangazi Üniversitesi Tip Fakültesi, Kalp ve Damar Cerrahisi Anabilim Dall, ESKIŞSEHİR.
}

\begin{abstract}
ÖZET
Aort diseksiyonu, aortun intima tabakasında oluşan bir yırtık sonucu intima ile mediya tabakası arasında yalancı bir lümenin oluşması olarak tanımlanan acil kardiyovasküler bir problemdir. Nadir görülen bir hastalık olduğundan tanısının hızlı ve doğru olarak konulabilmesi için şüphe indeksinin yüksek tutulması gerekir. Tanıya yönelik kullanılabilecek en önemli teşhis yöntemleri bilgisayarlı tomografi ve ekokardiyografidir. Tedavi başarısında hızlı tanı ve hızlı cerrahi girişim tedavinin köşe taşlarını oluşturmaktadır. Tedavi edilmeden geçen her saat için mortalite \%1-3 oranında artar. Aort diseksiyonu erken tanı ve hızlı tedavisi yapılabildiği takdirde tedavisi mümkün bir hastaliktır.

Acil servislerde aort diseksiyonunun erken tanısının konulabilmesi, ancak şüphe indeksinin yüksek tutulması ile sağlanabilir. Cerrahi tedavi uygulanan hastalarda prognozu etkileyen en önemli faktör, serebral perfüzyonun korunmasıdır. Cerrahi tedavi sirasında antegrat serebral perfüzyonun kullanılması klinik sonuçları olumlu etkiler.

$\mathrm{Bu}$ yazıda akut aort diseksiyonu tanısı ile cerrahi tedavisi yapılan 5 hastaya ait, erken ve orta dönem sonuçlar bildirildi.
\end{abstract}

Anahtar Kelimeler: Aort diseksiyonu, cerrahi tedavi, klinik sonuçlar

\begin{abstract}
Aortic dissection is an emergency cardiovascular problem that defined as the formation of a second false lumen between the aortic intima and media caused by a split on the intima layer. Because it is a rare disease, for prompt and accurate diagnosis a high index of suspicion is required. Computerized tomography and echocardiography are the most prominent diagnostic tools used for diagnosis of aortic dissection. Early diagnosis and treatment are crucial for survival. The mortality rate for untreated patients increases $1-3 \%$ per every hour. If early diagnosis and treatment of aortic dissection can be carried out, the treatment of the disease is possible. Early diagnosis of the disease can be achieved in the emergency departments which keep the index of suspicion for aortic dissection high. The most important issue effecting the prognosis in patients undergoing surgical treatment is cerebral perfusion preservation. We think that the use of antegrade cerebral perfusion during surgical treatment of aortic dissection positively effects clinical outcomes. In this paper, early and mid-term results of five patients who underwent surgical treatment with acute aortic dissection was reported.
\end{abstract}

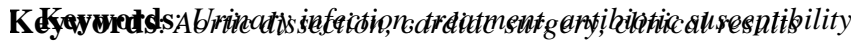

KÜ Tıp Fak Derg 2015; 17(1): 8-16

Geliş Tarihi / Received: 26.11.2014

Kabul Tarihi / Accepted: 22.12.2014
Yazışma Adresi / Correspondence: Cengiz OVALI Eskişehir Osmangazi Üniversitesi Tıp Fakültesi, Kalp ve Damar Cerrahisi Anabilim Dalı, EESKİŞEHİR

E-posta: doktorum@hotmail.com Tel: 0222 2392979/3400 


\section{GíRiș}

Aort diseksiyonu mortalite oranı yüksek acil kardiyovasküler bir problemdir. Aortanın intima tabakasında oluşan bir yırtık sonucu intima ile mediya tabakası arasında yalancı lümenin oluşması olarak tanımlanır (1). Bu konuda yapılan epidemiyolojik çalışmalarda hastalığın görülme sıklığı milyonda 5 ile 30 arasında bulunmuştur (2-4). Aort diseksiyonu acil servislerde nadir görülen bir kardiyavasküler problemdir. $\mathrm{Bu}$ nedenle tanısının hızlı ve doğru olarak konulabilmesi için şüphe indeksinin yüksek tutulması gerekir. Hastalar genellikle 40 yaş üzeri hipertansiyonu olan bireylerdir (5). Aort diseksiyonu hastalarının acil servise en sık başvuru yakınması ani başlayan, yırtılır tarzda olan ve interskapuler alana yayılım gösteren göğüs ağrısıdır. Arkus ve inen aortanın etkilendiği hastalarda özellikle sırt ağrısı ilk başvuru semptomu olabilir. Fakat çok farklı semptom ve bulgularla da (Akut miyokard infarktüsü, akut serebrovasküler olay, sol rekürren laringeal sinir paralizisine bağlı ses kısıklığı, senkop ve kardiyojenik şok gibi) bu hastaların başvurabileceği bilinmelidir $(5,6)$.

Aort diseksiyonundan şüphelenildiğinde acil serviste ilk istenecek tetkik akciğer grafisi olmalıdır. Hastaların \%60-70'inde mediasten bölgesinde genişleme vardır. Tanıya yönelik kullanılabilecek en önemli teşhis yöntemleri bilgisayarlı tomografi (BT) ve ekokardiyografidir. Bilgisayarlı tomografi ile diseksiyonun başlangıç ve bitiş seviyeleri, yalancı lümen ve diseksiyona ait fleb, diseksiyonun tutmuş olduğu segment içerisinde diğer damarların etkilenip etkilenmediği değerlendirilebilir (7). Bilgisayarlı tomografiye hızlı bir şekilde ulaşılamadığı durumlarda ekokardiyografi tanıda kullanılabilecek diğer teşhis yöntemidir. Acil serviste yatak başında hızlıca yapılacak bir Transtorasik ekokardiyografi (TTE) ile çıkan aortanın ilk 4-5 cm'lik segmentini tutan aort diseksiyonu olguları kolayca tanınabilir. Daha ileri seviyeden başlayan diseksiyon olgularını TTE ile tanımak mümkün olmayabilir. Yapılabiliyorsa transözefagial ekokardiyografi ile tüm torasik aorta diseksiyon açısından taranmalıdır. Hastalığın tanısı konulduğunda tedavisinin çok hılı bir şekilde yapılması gerekir. DeBakey Tip 1 ve tip 2 akut aort diseksiyonu için seçilecek tedavi şekli cerrahidir (8). Tedavi edilmeden geçen her saat için mortalite \%1-3 oranında $\operatorname{artar}(9)$. Tedavi başarısında hızlı tanı ve hızlı cerrahi girişim başarılı tedavinin köşe taşlarını oluşturmaktadır.

Biz bu yazıda merkezimizde akut aort diseksiyonu tanısı ile cerrahi tedavisi yapılan hastalara ait erken ve orta dönem sonuçlarının bildirilmesi amaçlandı.

\section{HASTALAR VE YÖNTEM}

$\mathrm{Bu}$ çalışmada, Eskişehir Osmangazi Üniversitesi Tıp Fakültesi Kalp Damar Cerrahisi Anabilim Dalında Nisan 2012 ile Temmuz 2014 tarihleri arasında aort diseksiyonu nedeniyle cerrahi tedavisi yapılan 5 hasta geriye dönük olarak değerlendirildi. Hastaların dosyalarından acil servise başvuru şikayetleri, fizik muayene bulguları, kardiyovasküler risk faktörleri bilgisayarlı tomografi ve ekokardiyografi bulguları kaydedildi. Aort diseksiyonu sınıflandırması için De Bakey sınıflaması kullanıldı. Bu sınıflamaya göre Tip 1 diseksiyon; çıkan aortadan başlayıp aortanın distaline yayılan, Tip 2 diseksiyon; sadece çıkan aortaya yayılan ve Tip 3 diseksiyon; sadece inen aortta lokalize diseksiyon olarak tanımlanır (8). Hastalara ait yapılan tanısal ve tedavi edici işlemler her olgu için aşağıda özetlendi.

Olgu 1: Altmış beş yaşında erkek hasta göğüs ağrısı nedeniyle acil servise başvurdu. Hastadan alınan tıbbi öyküden göğüs ağrısının 12 saat önce başlayan retrosternal bölgede lokalize, yayılım göstermeyen, şiddetli ve yırtıcı karakterde olan bir ağrı olduğu öğrenildi. Hastanın anamnezi derinleştirildiğinde 10 yıldır hipertansiyon tanısı ile anti-hipertansif tedavi 
almakta olduğu ve 25 yıldır 1 paket/gün sigara kullandığı öğrenildi. Yapılan fizik muayenede hasta bilinci açık ve endişeli görünümdeydi. Kan basıncı: 120/60 mmHg (sağ kol), 170/100 mmHg (sol kol) olarak ölçüldü. Sağ üst ekstremite nabızları zayıflamış olarak alındı, diğer ekstremite nabızları normal dolgunluktaydı. Kalp hızı 104/dk ve ritmik, solunumu dispneik ve takipneik görünümdeydi. Elektokardiyografisinde sinüs taşikardisi dışında patolojik bulgu yoktu. Aort diseksiyonu ön tanısı ile kontrastlı bilgisayarlı tomografisi çekildi. Bilgisayarlı tomografide trunkus brakiosefalik arter seviyesinden başlayan, retrograt olarak çıkan aortaya yayılım gösteren, antegrat olarak da sağ ana iliak arter distaline kadar uzanan Tip 1 diseksiyon saptandı (Şekil 1). Diseksiyon flebi trunkus brakiosefalik arterin ostiyumunda kısmen akımı engellerken, diğer arterlerde akımı engellemiyordu. Acil cerrahi kararı verilen hastaya IV (intravenöz) esmolol ve nitroprussid infüzyonu başlanarak operasyona alındı.

Operasyon Prosedürü: Genel anesteziyi takiben her iki radial arter kanülize edilerek her iki koldan invaziv kan basıncı takibi yapıldı. Sağ subklavien arterden ve diseksiyonun olmadığı sol femoral arterden arteriyal kanülasyon yapıld1. Sternotomiyi takiben vena kava inferior ve vena kava süperior kanüle edildi. Sağ atriyumdan retrograt kardiyopleji kanülü ve sağ superior pulmoner vene vent kanülü yerleştirildi. Brakiosefalik trunkus, sol karotis ve sol subklavian arter naylon teyple dönüldü. Kardiyopulmoner by-pass işlemine başlanılarak rektal $26-28{ }^{\circ} \mathrm{C}$ 'lik orta dereceli hipotermi sağlandı ve izotermik hiperkalemik kan kardiyoplejisi kullanıldı. Antegrad serebral perfüzyon sirasında $(700 \mathrm{ml} / \mathrm{dk})$ asendan aorta düzeyinde aortotomi yapıldı. Diseke segmentin koroner arter ostiyumların hemen üzerine kadar uzanım gösterdiği görüldü. İntimal yırtığın brakiosefalik arterin distalinden başladığı ve yalancı lümenin arkus aortaya doğru ilerleyip distale doğru devam ettiği gözlendi. Diseke olmuş aort kenarları fibrin doku yapıştırıcısı (tisseel) ile yapıştırıldıktan sonra internal ve eksternal teflon şeritler kullanılarak sandviç tekniğiyle sütüre edildi (Şekil 2a). $28 \mathrm{~mm}$ çapında politetrafloroetilen (PTFE) greft kullanılarak önce distal aort anastomozu yapıldı. Sonrasında sol subklaviyen arter ile sol ana karotis arter ostiyumları bir ada şeklinde grefte teflon şerit desteği ile anastomoze edildi. Bu anastomozun proksimalinden ana grefte kross klemp yerleştirilerek sistemik perfüzyona başlandı. Diseke segmentin sağ trunkus brakiosefalik artere doğru devam ettiği görüldüğünden buradan ana greftin proksimal - ön yüzüne $8 \mathrm{~mm}$ çapında $4 \mathrm{~cm}$ uzunluğunda PTFE greft bypass yapıldı. (Şekil 2b). Aort kapakta tutulum olmadığı için kapağa yönelik herhangi bir işlem yapılmadi. Ana greftin proksimal tarafi koroner ostiumların hemen üzerine anastomoze edildi. Dekanülasyon yapılarak kalp akciğer pompasından inotropik destek ile çıkıldı. Post-operatif 12. saatte ekstübe edildi. Akut renal yetmezlik gelişen hasta postoperatif 2. gün bir kez hemodiyalize alındı. Daha sonra renal fonksiyonları normale dönen hastada tekrar diyaliz ihtiyacı olmadı. Üçüncü gün servise alınan hasta 8. gün tam klinik düzelme sağlanmış olarak metoprolol $100 \mathrm{mg} /$ gün, amlodipin $10 \mathrm{mg} /$ gün ve asetil salisilik asit (ASA) $150 \mathrm{mg} /$ gün tedavisi ile taburcu edildi. Birinci ay ve 6 . ay poliklinik kontrolleri sorunsuzdu ve kan basıncı değerleri normal sinırlardaydı. 


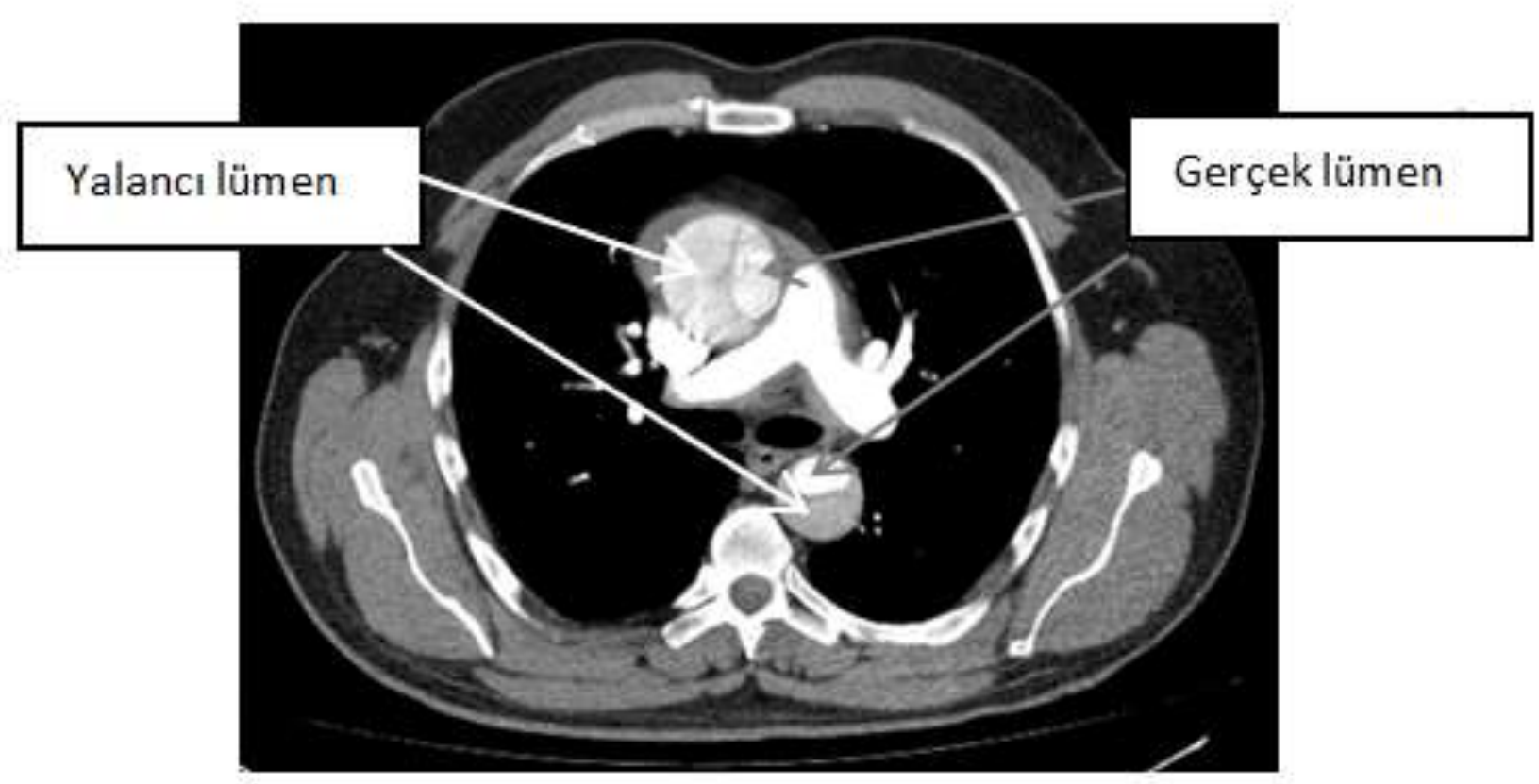

Şekil 1: Tip 1 aort diseksiyonlu hastada asendan aortada yalancı lümen ve flebe ait tomografi görüntüsü

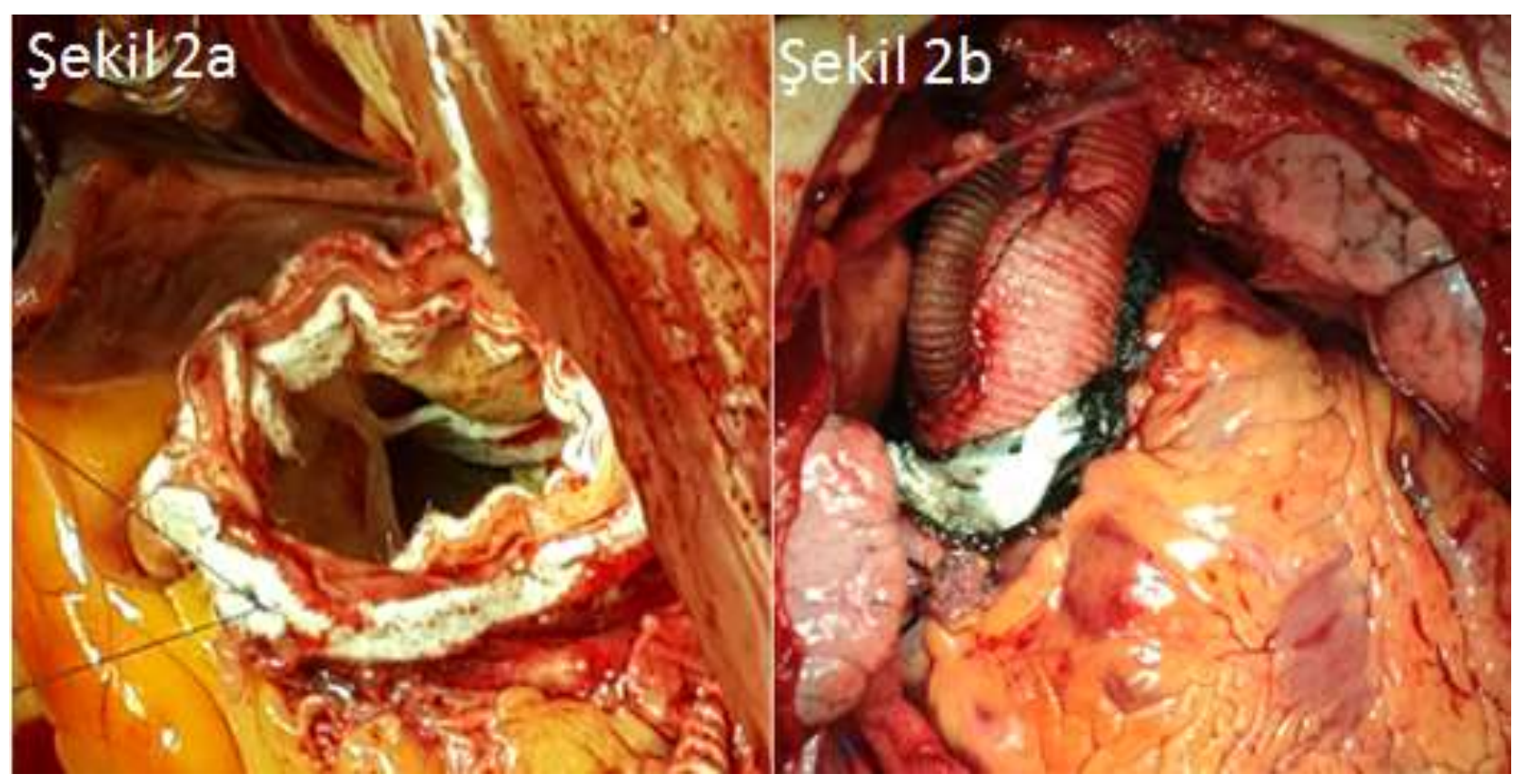

Şekil 2a ve b: Tip 1 aort diseksiyonlu hastada diseke lümenle gerçek lümenin teflon şeritler kullanılarak sandviç tekniği ile sütüre edilmesi (2a), Tip 1 aort diseksiyonlu hastada brakisefalik artere yapılmış olan greftin ana grefte anastomozuna ait operasyon görüntüsü $(2 b)$ 
Olgu 2: Başka bir sağlık kuruluşunun acil servisine başvuran 71 yaşında erkek hasta aort diseksiyonu tanısı ile hasta merkezimize kabul edildi. Hastanın başvuru yakınması şiddetli göğüs ve sırt ağrısı idi. Hastadan alınan tıbbi öyküden hipertansiyon, tip 2 diyabetes melitus ve koroner arter hastalığı olduğu öğrenildi. Yapılan fizik muayenesinde arteriyel kan basıncı: 160/100 mmHg (Sağ kol), 155/90 mmHg (Sol kol) olarak ölçüldü. Üst ve alt ekstremite nabızları eşit ve dolgun olarak alınd1, kalp hızı 88/dk ve ritmikti. Elektrokardiyografisinde (EKG) geçirilmiş inferiyor miyokard infarktüsünü düşündüren inferiyor derivasyonlarda patolojik Q dalgası ve sol ventrikül hipertrofisini düşündüren voltaj artışı vardı. Bilgisayarlı tomografide çıkan aortadan başlayıp her iki iliak arter proksimal segmentine kadar uzanım gösteren Tip 1 diseksiyon tesbit edildi. Hastanın TTE incelemesinde orta derecede aort yetersizliği vard 1 , çıkan aortada diseksiyon flebi ve yalancı lümene ait görünüm tesbit edildi. Acil cerrahi kararı verilen hasta kan basincı IV esmolol ve niproprussid infüzyonu ile kontrol altına alınarak operasyona alındı.

Operasyon Prosedürü: Birinci olguda yukarıda anlatıldığı şekilde operasyon hazırlıkları yapılarak kalp akciğer pompasına girildi. İntimal yırtığın koroner ostiyumlarının $2 \mathrm{~cm}$ üzerinden başlayıp aort köküne doğru retrograt uzanım gösterdiği ve buna bağlı aort kökünde dilatasyona yol açarak aort kapakta koaptasyon defektine bağlı aort yetmezliğine neden olduğu düşünüldü. Olgu 1 de olduğu gibi diseke olmuş aort kenarları fibrin doku yapıştırıcısı (tisseel) ile yapıştırıldıktan sonra internal ve eksternal teflon şeritler kullanılarak sandviç tekniğiyle sütüre edildi. Aort yetmezliğine yönelik aort kapak süspansiyonu yapıldıktan sonra $30 \mathrm{~mm}$ çapında $6 \mathrm{~cm}$ uzunluğunda PTFE greft ile asendan aort replasmanı yapıldı. Yoğun bakım ünitesine çıkarılan hasta post-operatif 8 . saatte ekstübe edildi. İkinci günde servise alınan hasta operasyon sonrası 7. gün metoprolol $100 \mathrm{mg} /$ gün, ramipril $5 \mathrm{mg} /$ gün, ASA $150 \mathrm{mg} /$ gün, atorvastatin 20 mg/gün, amlodipin $10 \mathrm{mg} /$ gün ve almakta olduğu oral antidiyabetik tedavisi ile taburcu edildi. Birinci ay ve 6 . ay poliklinik kontrollerinde sorunsuzdu.

Olgu 3: Başka bir sağlık kuruluşunun acil servisine başvuran 66 yaşında bayan hasta aort diseksiyonu tanıs1 ile hasta merkezimize kabul edildi. Tıbbi hikâyesinden kronik obstrüktif akciğer hastalığ1 (KOAH) ve hipertansiyonu olduğu öğrenildi. Genel durumu orta-kötü, bilinci açık olan hastanın semptomlarının 2 gün önce göğüs ağrısı şeklinde başladığı öğrenildi. Ağrının karakteri retrosternal bölgede en şiddetli olmakla beraber boynuna doğru yayılım gösterdiği ve nefes darlığının göğüs ağrısına eşlik ettiği öğrenildi. Yapılan fizik muayenesinde arteriyel kan basınc1: 80/50 mmHg (Sağ kol), 80/50 mmHg (Sol kol) olarak ölçüldü. Kalp sesleri derinden geliyordu, üst ve alt ekstremite nabızları eşit ve zayıf olarak alındı, kalp hızı 112/dk ve ritmikti. Dispneik ve takipneik görünümde idi, dinlemekle her iki akciğer bazal ve orta segmentlerde krepitan raller alınıyordu. Çekilen akciğer grafisinde mediasten ve kardiyotorasik oran artmıştı. Tomografisinde çıkan aortadan başlayıp her iki femoral artere kadar uzanım gösteren Tip 1 diseksiyon mevcuttu ve perikard boşluğunda kalbi komprese eden Sıvı varlığı saptandı. Kardiyak tamponad ve aort diseksiyonu tanıları konulan hasta acil operasyona alınd.

Operasyon Prosedürü: Birinci olguda anlatıldığ şekilde operasyon prosedürü uygulandı. Perikard açıldığında yaygın hemoraji ve sol koroner kuspis üzerinden diseksiyon lümeninin perikard boşluğuna açıldığı görüldü. $28 \mathrm{~mm}$ PTFE greft ve $21 \mathrm{~mm}$ mekanik protez kapak kullanılarak Benthall prosedürü uygulanarak aort kökü ve asendan aorta replase edildi. Kalp akciğer pompasından inotropik desteğe rağmen çıkılamadı ve hasta kaybedildi. 
Olgu 4: Yetmiş iki yaşında erkek hasta sırt ağrısı nedeniyle acil servise başvurdu. Hastanın anamnezinden televizyon izlerken aniden başlayan ve çok şiddetli olarak tanımladığı interskapuler alanda sırt ağrısı olduğunu ifade etti. Tıbbi hikâyesinden $\mathrm{KOAH}$ dışında sistemik bir rahatsızlı̆̆ının olmadığı öğrenildi. Ağrının geçmemesi üzerine acil servise başvuran hastanın fizik muayenesinde muayenesinde arteriyel kan basınc1: 150/90 mmHg (Sağ kol), 150/90 mmHg (Sol kol) olarak ölçüldü. Üst ve alt ekstremite nabızları eşit ve dolgun olarak alındı, kalp hızı 80/dk ve ritmikti. Akciğer grafisinde KOAH ile uyumlu olabilecek hiperinflasyon dışında patolojik bulgu yoktu. Ekokardiyografik incelemede diseksiyona ait flep ve yalancı lümen gözlendi, aort yetmezliği yoktu. Bilgisayarlı tomografisinde çıkan aortadan başlayıp trunkus brakiosefalik arterden hemen önce sonlanan Tip 2 diseksiyon saptandı. Acil cerrahi kararı verilen hasta kan basıncı ve kalp hızı kontrol altına alınarak operasyona alındı.

Operasyon Prosedürü: Birinci olguda anlatıldığ1 şekilde operasyon prosedürü uygulandi. Aortotomi yapılan hastada intimal yırtığın aorta ön yüzünde olduğu görüldü. Flep koroner ostiyumların üzerinde ve innominate arter öncesinde sonlanıyordu. Diseksiyonun olduğu asendan aortaya $32 \mathrm{~mm}$ çapında PTFE greft replase edildi. Yoğun bakım ünitesine çıkarılan hasta post-operatif 24. saatte ekstübe edilebildi. Arteriyel kan gazında yeterli oksijen satürasyonu sağlanamaması nedeniyle geç ekstübe edildi. KOAH'a yönelik bronkodilatatör tedavi ve non-invaziv mekanik ventilasyon desteği altında 96 saat yoğun bakım ünitesinde takip edildi. Solunum yetmezliği nedeniyle entübe edildi. Mekanik ventilatör desteği altında izlene hasta reanimasyon yoğun bakım ünitesine alındı. Takibinde akciğer enfeksiyonu gelişen hasta yoğun solunum desteği ve antibiyotik tedavisine rağmen genel durumu giderek kötüleşti. Yatışını takiben 11. günde solunu yetmezliğinden hasta kaybedildi.
Olgu 5: Kırk beş yaşında erkek hasta göğüs ağrısı nedeniyle çekilen akciğer grafisinde mediastende ileri derecede genişleme olması nedeniyle çekilen tomografisinde çıkan aort anevrizması ve diseksiyon ile uyumlu olabilecek şüpheli flep varlığı saptandı. Anevrizma çıkan aortadan innominate artere kadar uzanım gösteriyordu ve en geniş yerinde $9 \mathrm{~cm}$ olarak ölçüldü. Ekokardiyografisinde çıkan aorta dilate görünümde idi, aort kökü $32 \mathrm{~mm}$ ölçüldü, aort kapak triküspis yapıda ve hafif aort yetmezliği vardı. Hastanın tıbbi hikâyesinden 10 yıldır olan hipertansiyon ve 20 yıldır olan 1 paket/gün sigara dışında kardiyovasküler risk faktörü yoktu. Çıkan aorta anevrizmasına yönelik cerrahi tedavi kararı verilen hasta elektif şartlarda operasyona alındı.

Operasyon Prosedürü: Genel anesteziyi takiben femoral arter kanüle edilerek kalp akciğer pompasına girildi. Aortotomi yapıldıktan sonra sağ koroner kuspisin yaklaşık $3 \mathrm{~cm}$ üzerinden başlayan $4 \mathrm{~cm}$ yukarıya doğru uzanım gösteren kronik diseksiyon tesbit edildi. Anevrizmatik asendan aorta rezeke edilerek çıkartıldı ve $32 \mathrm{~mm}$ çapında PTFE greft ile replase edildi. Yoğun bakım ünitesine çıkarılan hasta post-operatif 6. saatte ekstübe edildi. İkinci gün servise çıartılan hasta operasyon sonrası 7. Günde karvedilol $50 \mathrm{mg} /$ gün, amlodipin $10 \mathrm{mg} /$ gün ve ASA $150 \mathrm{mg} /$ gün tedavisi ile taburcu edildi. Birinci ay ve 6 . ay poliklinik kontrollerinde sorunsuzdu.

\section{TARTIŞMA}

Çalışmamızda akut aort diseksiyonu tanısı ile cerrahi tedavisi yapılan hastalara ait erken ve orta dönem sonuçlar bildirildi. Acil cerrahi tedavisi yapılan toplam 5 hastadan 1 tanesi operasyon bitiminde kalp akciğer pompasından çıkamaması nedeniyle akut kalp yetmezliğinden kaybedildi. Dört tanesinde operasyon başarılı bir şekilde tamamlandı. Bu hastalardan 1 tanesi $\mathrm{KOAH}$ alevlenmesi ve akciğer enfeksiyonuna bağlı operasyondan 11 gün sonra kaybedildi. Sonuç olarak 
geri kalan 3 hasta taburcu edildi ve ilk 6 aylik takiplerinde herhangi bir sorun yaşanmadı.

Acil cerrahi tedavisini yaptığımız 5 adet aort diseksiyonu olgularının tamamı DeBakey sınıflandırmasına göre Tip 1 ve tip 2 aort diseksiyonu olguları idi. Aort diseksiyonu için en kabul gören siniflandirmalar DeBakey ve Stanford sınıflandırmalarıdır. DeBakey sınıflandırmasının nasıl yapıldığı metot kısmında bahsedildi. Stanford sınıflandırmasına göre aort diseksiyonu Tip A ve Tip B olarak 2 sınıfa ayrılır. Tip A diseksiyon, intimal yırtığını yerine bakılmaksızın asendan aortanın tutulduğu diseksiyon tipi, Tip B diseksiyon ise sol subklavien arterin distalinden başlayan diseksiyon tiplerini kapsar. Buna göre DeBakey Tip 1 ve tip 2 aort diseksiyonu, Stanford sınıflamasına göre Tip A sınıfına karşılık gelirken, DeBakey Tip 3 diseksiyon ise Stanford sınıflamasına göre Tip B diseksiyona karşılık gelir. Tip 3 diseksiyon olguları için seçilecek güncel tedavi şekli endovasküler girişim ve medikal tedavi iken, tip 1 diseksiyonlarda ise standart tedavi şekli acil cerrahi girişimdir (8). Aort diseksiyonu için ilk başarılı cerrahi, kalp akciğer pompasının keşfi ile DeBakey ve ark. tarafindan 1955 yılında başarıyla uygulanmıştır (10).

Günümüzde aort diseksiyonunun acil cerrahi tedavisi için birkaç farklı cerrahi teknik uygulanmaktadır. Bu tekniklerin hepsinin hedefi başarılı diseksiyon cerrahisi ile birlikte serebral ve diğer hayati organların korunmasıdır. $\mathrm{Bu}$ konuda yapılan çalışmaların bir kısmında hipotermik total sirkülatuar arrest süresinin 40 dakikayı geçmesi durumunda, bunlara ek olarak retrograd serebral perfüzyon kullanılması önerilmektedir (11-13). Bazı çalışmalarda ise derin hipotermik sirkülatuvar arrest ve retrograd serebral perfüzyon olmaksızın aksiler arter kanülasyonuyla antegrat yolla serebral perfüzyonu sağlayarak serebral korumanın daha optimal olabileceğini ileri sürmüşlerdir (14-17). Biz de merkezimizde aksiller kanülasyonla antegrat yolla serebral perfüzyonu sağlayarak yapılan cerrahi tekniği uyguluyoruz. Tekniğin nasıl uygulandığı olgu 1 için yazılan operasyon prosedürü içerisinde ayrıntılı olarak anlatıldı. Diseksiyon ameliyatlarında kalp dışı prognozu etkileyen en önemli komplikasyonların başında serebral perfüzyon bozukluğu gelir. Hagi ve ark.'nın yapmış oldukları çalışmada, antegrat serebral perfüzyon (ASP) ile nörolojik komplikasyonların en az olduğunu göstermişlerdir (15). Di Eusanio ve ark. yapmış oldukları başka bir çalışmada da ASP'nin nörolojik komplikasyonları azaltmanın yanısıra derin hipotermiden kaynaklanan koagülasyon sistemi ve sistemik komplikasyonlarını azalttığını bildirmişlerdir (14). Bizim olgularımızda da postoperatif dönemde nörolojik komplikasyon ve koagülasyon bozukluğunu düşündüren komplikasyon gelişmedi. Birinci olguda postoperatif 2. günde akut böbrek yetmezliği gelişmesi nedeniyle $1 \mathrm{kez}$ hemodiyalize alınması gerekti. $\mathrm{Bu}$ hastanın da akut böbrek yetmezliği sonrasında hızla düzelerek böbrek fonksiyonları tamamen normale dönmüştü.

Aort diseksiyonu geçiren hastaların büyük kısmı hızlı tanı ve tedavi imkânlarına ulaşamadan yaşamını yitirmektedir. Aort diseksiyonu için tanı ile cerrahi tedavi arasında geçen süre ne kadar uzarsa tedavi başarısı o kadar azalır. Bu nedenle özellikle acil servise başvuran hastalarda aort diseksiyonu olasılığı açısından yüksek riskli olguların erken tanısını koymak önemlidir. Göğüs ve/veya sırt ağrısı ile başvuran hastalarda ayırıcı tanıda aort diseksiyonu mutlaka düşünülmelidir. Ayrıca senkop, hemipleji, anksiyete gibi atipik yakınmalarında aort diseksiyonunun bir bulgusu olabileceği göz önünde tutulmalıdır $(5,6)$.

Hipertansiyon, aterosklerotik kalp hastalığı, biküspit aorta, aort koarktasyonu, Marfan sendromu ve gebelik gibi durumların varlığında aort diseksiyonu olasılığı daha yüksektir (18). Bu gibi durumlarda aort diseksiyonu ayırıcı tanısında fizik muayenede dikkat edilmesi gereken bazı temel kurallar vardır. Ekstremiteler arasındaki kan basıncı ve nabız farkı aort 
diseksiyonu ön tanısı için değerli bir muayene bulgusudur. Bizim olgularımızdan birinde de diseksiyon flebinin innominate arteri tutmasına bağlı olarak sağ kol ile sol kol arasında önemli basınç farkı vardı. Diğer muayene bulgusu diseksiyonun perikarda açılmasına bağlı olarak kardiyak tamponad gelişmesi durumunda taşikardi, hipotansiyon ve kalp seslerinin derinden duyulduğu triyaddır. Bizim olgularımızdan olgu 3 de diseksiyonun yolaçtığı kardiyak tamponad tablosunda başvurmuştu.

Hastadan alınan iyi bir anamnez, fizik muayene ve akciğer grafisinde aort diseksiyonundan kuşkulanılan hastalarda tanıda istenecek ilk tetkik bilgisayarlı tomografi olmalıdır. Günümüzde kolay ulaşılabilir olması, hızlı sonuç vermesi, kolay yorumlanması ve duyarlılığının ve özgülüğünün yüksek olması aort diseksiyonu tanısında tomografiyi ön plana çıkarmaktadır (19). Bizim olgularımızın da hepsinin tanısı BT ile kesinleştirilmişti. Diseksiyon şüphesi olan olgularda eğer hastane imkânları elveriyorsa bu hastaların tomografisi elde edilmelidir. Ekokardiyografi de diseksiyon tanısını koymada etkili olabilecek diğer bir tanı yöntemidir. Özellikle günümüzde acil servislerde amaca yönelik ekokardiyografi kullanımı yaygınlık kazanmaktadır. Bu şekilde bir yaklaşımla komple bir kardiyak ekokardiyografik değerlendirme değil diseksiyona yönelik ekokardiyografik inceleme acil servislerde tanı oranını artırabileceğini düşünüyoruz. Ayrıca ekokardiyografi ile aort kökü ve aort kapağın detaylı değerlendirmesi mümkündür (20).

Sonuç olarak;

1. Aort diseksiyonu erken tanı ve hizlı tedavisi yapılabildiği takdirde tedavisi mümkün bir hastalıktır. Acil servislerde aort diseksiyonu için şüphe indeksinin yüksek tutulması ile hastalığın erken tanısı konabilir.

2. Cerrahi tedavi uygulanan hastalarda prognozu etkileyen en önemli husus serebral perfüzyonun korunmasıdır. Cerrahi tedavi sırasında antegrat serebral perfüzyonun kullanılmasının klinik sonuçları olumlu etkileyeceğini düşünüyoruz.

\section{KAYNAKLAR}

1. Nienaber CA, Eagle KA. Aortic dissection: new frontiers in diagnosis and management: Part I: from etiology to diagnostic strategies. Circulation. 2003; 108: 628 .

2. Bickerstaff LK, Pairolero PC, Hollier LH, Melton LJ, Van Peenen HJ, Cherry KJ, Joyce JW, Lie JT. Thoracic aortic aneurysms: a population-based study. Surgery. 1982; 92: 1103.

3. Meszaros I, Morocz J, Szlavi J, Schmidt J, Tornoci L, Nagy L, Szep L. Epidemiology and clinicopathology of aortic dissection. Chest. 2000; 117: 1271.

4. Clouse WD, Hallett JW Jr, Schaff HV, Spittell PC, Rowland CM, Ilstrup DM, Melton LJ 3rd. Acute aortic dissection: population-based incidence compared with degenerative aortic aneurysm rupture. Mayo Clin Proc. 2004; 79: 176.

5. Hagan PG, Nienaber CA, Isselbacher EM, Bruckman D, Karavite DJ, Russman PL, Evangelista A, Fattori R, Suzuki T, Oh JK, Moore AG, Malouf JF, Pape LA,Gaca C, Sechtem U, Lenferink S, Deutsch HJ, Diedrichs H, Marcos y Robles J, Llovet A, Gilon D, Das SK, Armstrong WF, Deeb GM, Eagle KA. The International Registry of Acute Aortic Dissection (IRAD): new insights into an old disease. JAMA. 2000; 283: 897.

6. Nallamothu BK, Mehta RH, Saint S, Llovet A, Bossone E, Cooper JV, Sechtem U, Isselbacher EM, Nienaber CA, Eagle KA, Evangelista A. Syncope in acute aortic dissection: diagnostic, prognostic, and clinical implications. Am J Med. 2002; 113: 468.

7. Erbel R, Engberding R, Daniel W, Roelandt J, Visser C, Rennollet $H$. Echocardiography in diagnosis of aortic dissection. Lancet. 1989; 1: 457. 
8. Daily PO, Trueblood HW, Stinson EB, Wuerflein RD, Shumway NE. Management of acute aortic dissections. Ann Thorac Surg. 1970; 10: 237.

9. Anagnostopoutos CE, Prahhakar MJS, Kittle CF: Aortic dissections and dissecting aneurysms. Am J Cardiol. 1972; 30: 263.

10. Debakey ME, Cooley DA, Creech O: Surgical consideration of dissection aneurysm of the aorta. Ann Surg. 1955; 142: 586-91.

11. Sabik JF, Lytle BW, McCarthy PM, Cosgrove DM. Axillary artery: an alternative site of arterial cannulation for patients with extensive aortic and peripheral vascular disease. $\mathbf{J}$ Thorac Cardiovasc Surg. 1995; 109: 885-90.

12. Mazzola A, Gregorini R, Villani C, Di Eusanio M. Antegrade cerebral perfusion by axillary artery and left carotid artery inflow at moderate hypothermia. Eur J Cardiothorac Surg. 2002; 21: 930-1.

13. Buket S, Apaydın A, Hamulu A, Özbaran M, Alayunt A, Yüksel M, Bilkay Ö, Durmaz İ, Aşkar F, Sakarya M. Akut Aort Diseksiyonlarında Cerrahi Tedavi. TGKKDC Dergisi. 1995; 3(2): 147-52.

14. Di Eusanio M, Wesselink RM, Morshuis WJ, Dossche KM, Schepens MA. Deep hypothermic circulatory arrest and antegrade selective cerebral perfusion during ascending aortahemiarch replacement: a retrospective comparative study. J Thorac Cardiovasc Surg. 2003; 125: 849-54.

15. Hagl C, Ergin MA, Galla JD, Lansman SL, McCullough JN, Spielvogel D, Sfeir P, Bodian CA, Griepp RB. Neurologic outcome after ascending aorta-aortic arch operations: effect of brain protection technique in high-risk patients. $\mathbf{J}$ Thorac Cardiovasc Surg. 2001; 121: 1107-21.

16. Di Bartolomeo R, Di Eusanio M, Pacini D, Pagliaro M, Savini C, Nocchi A, Pierangeli A. Antegrade selective cerebral perfusion during surgery of the thoracic aorta: risk analysis. Eur J Cardiothorac Surg. 2001; 19: 765-70.
17. Emrecan B, Y1lık L, Özsöyler İ, Lafc1 B, Kestelli M, Göktoğan T, Özbek C, Gürbüz. A. Stanford tip A aort diseksiyonlarında aksiller arter kanülasyonu. TGKDC Dergisi. 2006; 14(1): 3-8.

18. Januzzi JL, Isselbacher EM, Fattori R, Cooper JV, Smith DE, Fang J, Eagle KA, Mehta RH, Nienaber CA, Pape LA; International Registry of Aortic Dissection (IRAD). Characterizing the young patient with aortic dissection: results from the International Registry of Aortic Dissection (IRAD). J Am Coll Cardiol. 2004; 43: 665.

19. Örgüç Ş, Demirpolat G, Elçin F, Gürgan U. Helical computed tomography and 3-D Imaging in the diagnosis of aorta pathologies, TGKDC.Dergisi. 1999; 7(4): 270-5.

20. Sarıtaş A, Güneş H, Kandiş H, Çıkman M, Çandar M, Korkut S, Kul C. A Retrospective Analysis of Patients Admitted to our Clinic with Aortic Dissection. JAEM. 2011; 10(4): 152-5. 